\title{
Thoracoscopic Approach for Congenital Diaphragmatic Hernia: A Useful Tool in Diagnosis and Treatment of Unexpected Associated Lung Lesion
}

\author{
Mario Lima ${ }^{1}$ Michela Maffi ${ }^{1}$ Tommaso Gargano ${ }^{1} \quad$ Giovanni Ruggeri $^{1} \quad$ Michele Libri $^{1} \quad$ Francesca Destro $^{1}$ \\ ${ }^{1}$ Department of Pediatric Surgery, S. Orsola Hospital, University of \\ Bologna, Bologna, Italy \\ Address for correspondence Michela Maffi, MD, Department of \\ Pediatric Surgery, S. Orsola Hospital, via Massarenti 11, Bologna \\ 40138, Italy (e-mail: michela.maffi@libero.it).
}

Eur J Pediatr Surg Rep 2016;4:10-12.

\begin{abstract}
We report the case of a neonate affected by prenatally diagnosed congenital diaphragmatic hernia $(\mathrm{CDH})$, treated by thoracoscopy. During the procedure, we detected an

Keywords

- thoracoscopy

- congenital diaphragmatic hernia

- pulmonary sequestration associated extralobar pulmonary sequestration (EPS), which was preoperatively undiagnosed, and we removed it. EPS has been shown to be associated with CDH in up to 15 to $40 \%$ of cases. A possible explanation hypothesized is that pulmonary sequestration, which develops at 4 to 5 weeks of gestation, can disturb the fusion of the diaphragm and closure of the pleuroperitoneal canal. The thoracoscopic approach permitted us to identify the thoracic EPS that probably would have been otherwise missed.
\end{abstract}

\section{New Insights and Importance for the Pediatric Surgeon}

The case report describes the usefulness of thoracoscopy as diagnostic and therapeutic tool in case of diaphragmatic hernia associated with undiagnosed lung malformation. Thoracoscopy allows to explore thoracic cavity looking for lung lesions that are associated to diaphragmatic hernia in $15-40 \%$ of cases and to remove them.

\section{Introduction}

Pulmonary sequestration (PS) is a rare developmental disorder characterized by the presence of a nonfunctioning lung parenchyma that lacks normal tracheobronchial tree connection and is supplied by a systemic artery. ${ }^{1}$

Congenital diaphragmatic hernia $(\mathrm{CDH})$ is a malformation characterized by a diaphragmatic defect through which the abdominal viscera migrate into the chest during fetal life. ${ }^{2}$

The association between PS and CDH has been previously described. $^{1-7}$ We report the case of a neonate affected by prenatally diagnosed CDH treated by thoracoscopy. During the procedure, we detected an associated extralobar PS, which was preoperatively undiagnosed, and removed it.

\section{Case Report}

A female infant was delivered by elective cesarean section at 35 weeks of gestation and was referred to our department for prenatal diagnosis of left diaphragmatic hernia detected at 32 weeks of gestation by ultrasounds and characterized by a lung-to-head ratio (LHR) of 1.6. Weight at birth was $3,400 \mathrm{~g}$, and Apgar index was 9 at 1 minute and 10 at 5 minutes, respectively.
License terms

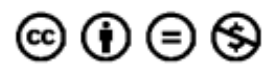

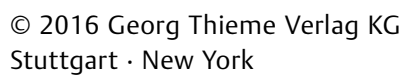
Stuttgart · New York

December 21, 2015

accepted after revision

February 12, 2016

published online

April 5, 2016

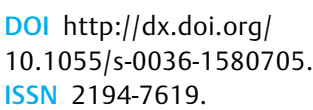

DOI http://dx.doi.org/ 10.1055/s-0036-1580705. ISSN 2194-7619. 


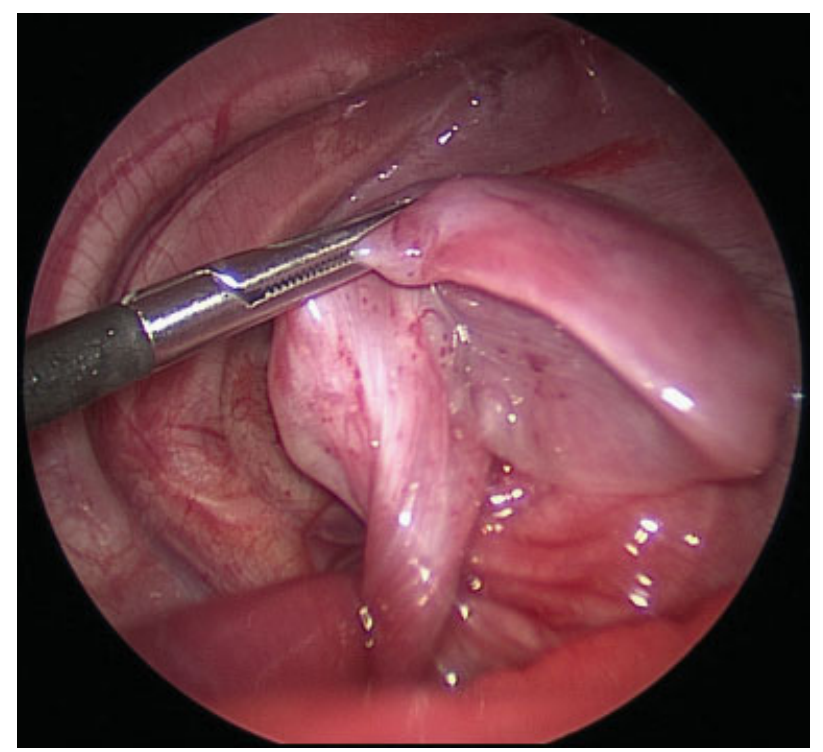

Fig. 1 Extralobar sequestration with its feeding artery.

At birth, the newborn underwent nasotracheal intubation and high-frequency oscillatory ventilation, positioning of a nasogastric tube, and chest X-ray that confirmed prenatal diagnosis. During the first day of life, further malformations were excluded: cardiological evaluation and head ultrasound were normal.

The patient maintained clinical stability, so we decided for surgical correction through thoracoscopic approach on the second day of life. The patient was placed in right lateral decubitus position. A 5-mm trocar was positioned in the fifth intercostal space over the middle axillary line, and two further operative trocars ( $3 \mathrm{~mm}$, reusable) were placed in the sixth intercostal space over the anterior and posterior axillary line, respectively. Capnothorax was created with a

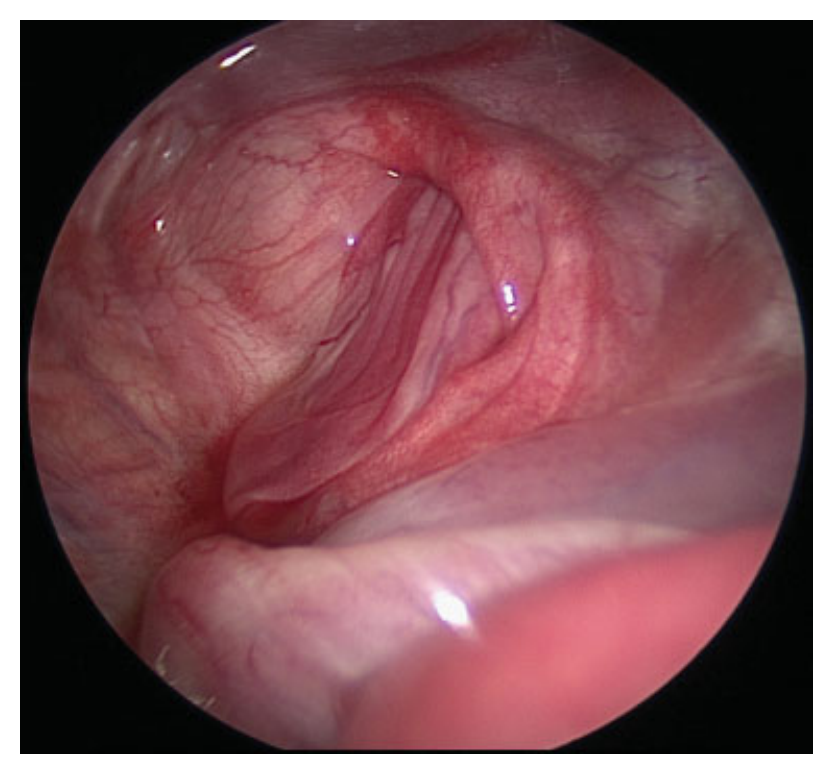

Fig. 2 Diaphragmatic defect after reduction of herniated structures.

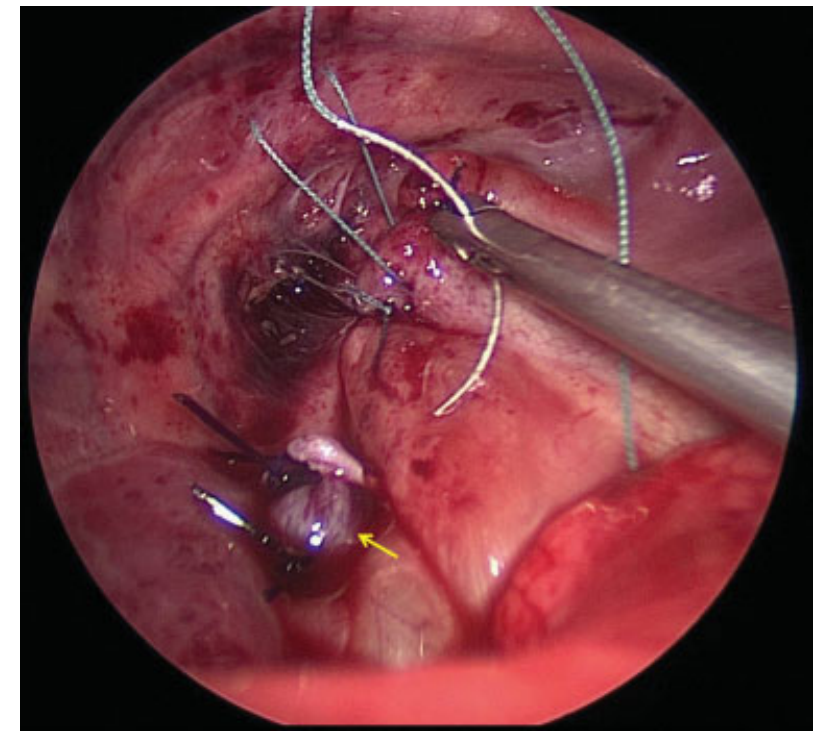

Fig. 3 Diaphragmatic defect repair with interrupted suture. The aberrant vessel has been ligated with two endoloops (arrow).

$6 \mathrm{mmHg}$ pressure and $0.5 \mathrm{~L} / \mathrm{min}$ flow, and maintained with intermittent insufflation to reduce side effects of $\mathrm{CO}_{2}$ absorption. Once entered in the pleural cavity, we noted a diaphragmatic hernia with a sac. A basal extralobar sequestration was also detected and removed after ligation of the feeding artery with two endoloops (-Fig. 1). The sac was left to prevent bowel rising during closure. The diaphragmatic defect was repaired with an interrupted 3/0 braided polyester suture (Ethibond) (-Figs. 2 and 3). The sequestration was exteriorized through a minimal enlargement of the first trocar site. Operative time was 130 minutes. After the procedure, a chest tube was left for 3 days. The postoperative course was uneventful. The patient underwent first follow-up chest X-ray after 2 months, and she is currently asymptomatic without radiologic signs of recurrence (6-month follow-up).

\section{Discussion}

PS includes two forms: intralobar PS (within the normal parenchyma), which is the most common form, and extralobar pulmonary sequestration (EPS). ${ }^{1}$ EPS has its own pleural covering and can be located inside or outside the thorax. PS is often associated with other congenital anomalies. The associations are more common in the extralobar type and include congenital pulmonary airway malformation, configuring a lesion termed as "hybrid lesion," congenital heart disease, and $\mathrm{CDH}$ in up to 15 to $40 \%$ of cases. ${ }^{7-10}$ A possible explanation is the interference related to the presence of a sequestered lung mass with the fusion of diaphragmatic components (mechanical obstacle). ${ }^{7,11}$

In recent years, there has been speculation on the prognosis associated with the two simultaneous defects (CDH and PS). ${ }^{7}$ PS can be associated with pulmonary hypoplasia, and being a space-occupying lesion, it could constitute a further obstacle to lung development. ${ }^{3,8}$ 
Indeed, the prognosis of PS combined with $\mathrm{CDH}$ remains unclear, and although there is not sufficient evidence regarding the influence of PS on CDH prognosis, some authors hypothesized that PS acts as a protective factor during pregnancy and probably improves the prognosis of patients with $\mathrm{CDH}^{7}$ Two possible explanations for this improved outcome may be given: (1) PS acts as an anatomical barrier to the rise of the abdominal viscera; (2) PS causes a mediastinal shift leading to an underestimation of LHR, thus distorting the prognosis that seems poorer. ${ }^{7}$

Prenatal identification of both CDH and PS is possible, and frequently occurs. ${ }^{7}$ In our case, prenatal diagnosis of concurrent $\mathrm{CDH}$ and $\mathrm{PS}$ was not possible probably because herniated organs obscured the presence of a sequestered lung mass.

The treatment of choice of a symptomatic EPS in addition to a $\mathrm{CDH}$ is surgical excision. ${ }^{1,2}$ However, some authors recommend observation of asymptomatic EPS, as these lesions rarely produce complications. ${ }^{12}$ We believe that resection should be the treatment of choice in all cases since there are hybrid lesions misdiagnosed as pure sequestrations and one can never be sure that the lesion will remain asymptomatic. ${ }^{4}$ The most frequent argumentation for removal is the prevention of recurrent infections and malignancy. The estimated risk for complication in asymptomatic patients with congenital lung lesions is $3.2 \%$. Malignancy has been reported to be associated to cystic lesions, in particular to type I congenital cystic adenomatoid malformation in $1 \%$ of cases. ${ }^{12}$ Although the risk is quite low, in case of recurrent infections or neoplastic evolution, the previous "wait and see" approach would be difficult to justify. Regarding the surgical approach, minimally invasive alternatives to the traditional surgical technique have been recently proposed, although the best approach to $\mathrm{CDH}$ is controversial. ${ }^{2}$ Recently, hypercapnia and acidosis during thoracoscopy in newborns have been reported. ${ }^{13,14}$ In our case, we used $\mathrm{CO}_{2}$ insufflation at the beginning of the procedure to facilitate reduction of herniated organs only for brief periods to improve visibility.

The distinction between a diaphragmatic hernia with sac and a congenital localized eventration may be difficult. Sac removal seems to be associated with a lower recurrence rate, ${ }^{15}$ but during thoracoscopy the presence of a sac can facilitate reduction, can lessen visceral trauma, and keeps the two cavities separate. ${ }^{2}$ According to a recent survey among the International Pediatric Endosurgery Group members, ${ }^{16}$ $22 \%$ of surgeons declared to leave the sac in place during the thoracoscopic repair of $\mathrm{CDH}$, so this approach is quite accepted even if in a minority of cases.

The feeding artery of PS often rises from the aorta or major arteries. Accurate closure of this vessel is mandatory to avoid postoperative bleeding, which can be life-threatening. ${ }^{17}$ In case of EPS, vessel sealing can be achieved with different devices such as Ligasure, clips, and ligation. In this case, since the EPS was of limited size, we closed the feeding artery with two endoloops and cut the vessel with cold scissors to avoid thermic damage of the ligatures.

We would probably have missed the PS using a different surgical approach (classical laparotomy), as during the laparotomic approach the posterior position of the diaphragmatic defect makes it hard to inspect the entire hypoplastic lung that is atelectatic and displaced in the upper part of the chest.

\section{Conclusion}

The thoracoscopic approach for $\mathrm{CDH}$ offers the advantage to easily diagnose and treat associated lung lesions.

\section{Conflict of Interest}

None.

\section{References}

1 Durell J, Lakhoo K. Congenital cystic lesions of the lung. Early Hum Dev 2014;90(12):935-939

2 McHoney M. Congenital diaphragmatic hernia, management in the newborn. PediatrSurgInt 2015;31(11):1005-1013

3 Harris K. Extralobar sequestration with congenital diaphragmatic hernia: a complicated case study. Neonatal Netw 2004;23(6):7-24

4 Luet'ic T, Crombleholme TM, Semple JP, D'Alton M. Early prenatal diagnosis of bronchopulmonary sequestration with associated diaphragmatic hernia. J Ultrasound Med 1995;14(7):533-535

5 Hamrick SEG, Brook MM, Farmer DL. Fetal surgery for congenital diaphragmatic hernia and pulmonary sequestration complicated by postnatal diagnosis of transposition of the great arteries. Fetal DiagnTher 2004;19(1):40-42

6 Urushihara N, Nakagawa Y, Kawashima K, Fukazawa T, Watanabe Y, Todani T. Congenital right diaphragmatic hernias through posterolateral and anterolateral defects associated with extralobar pulmonary sequestration: a case report. J PediatrSurg 1997;32(1):101-102

7 Grethel EJ, Farrell J, Ball RH, et al. Does congenital diaphragmatic hernia associated with bronchopulmonary sequestration portend a better prognosis? Fetal DiagnTher 2008;23(4):250-253

8 Diesen DL, Megison S. Congenital diaphragmatic hernia with associated pulmonary sequestration. J Pediatr 2014;165(6):1268-1268.e1

9 Ankola PA, Morkos A. Pathology teach and tell: neonatal ELS. PediatrPatholMol Med 2003;22(2):175-179

10 DeParedes CG, Pierce WS, Johnson DG, Waldhausen JA. Pulmonary sequestration in infants and children: a 20-year experience and review of the literature. J PediatrSurg 1970;5(2):136-147

11 Lee MY, Won HS, Shim JY, et al. Protective effect of fetal pulmonary sequestration in two cases of postnatal manifestation of congenital diaphragmatic hernia. Ultrasound ObstetGynecol 2012;39(6): 719-722

12 Stanton M, Njere I, Ade-Ajayi N, Patel S, Davenport M. Systematic review and meta-analysis of the postnatal management of congenital cystic lung lesions. J PediatrSurg 2009;44(5):1027-1033

13 Bishay M, Giacomello L, Retrosi G, et al. Hypercapnia and acidosis during open and thoracoscopic repair of congenital diaphragmatic hernia and esophageal atresia: results of a pilot randomized controlled trial. Ann Surg 2013;258(6):895-900

14 Pierro A. Hypercapnia and acidosis during the thoracoscopic repair of oesophageal atresia and congenital diaphragmatic hernia. J PediatrSurg 2015;50(2):247-249

15 Hajer GF, vdStaak FH, de Haan AF, Festen C. Recurrent congenital diaphragmatic hernia; which factors are involved? Eur J PediatrSurg 1998;8(6):329-333

16 Lacher M, St Peter SD, Laje P, Harmon CM, Ure B, Kuebler JF. Thoracoscopic $\mathrm{CDH}$ repair-a survey on opinion and experience among IPEG members. J LaparoendoscAdvSurg Tech A 2015; 25(11):954-957

17 Hall NJ, Chiu PP, Langer JC. Morbidity after elective resection of prenatally diagnosed asymptomatic congenital pulmonary airway malformations. Pediatr Pulmonol 2016;51(5):525-530 